\title{
LANGUAGE CHOICE IN MULTILINGUAL CONTEXT: THE USE OF L1 IN THE HOSPITALITY ENGLISH COURSES
}

\author{
Ni Putu Era Marsakawati \\ Ganesha University of Education, \\ Bali, Indonesia \\ marsakawatiera@gmail.com
}

\begin{abstract}
The present study presents the perception of lecturers on the use of the first language in the foreign language classroom, particularly in a tourism vocational institution in a multilingual context. The participants were 2 lecturers teaching Hospitality English: one lecturer was teaching English for Front Office and one lecturer was teaching English for Food and Beverage. The data were collected through administering questionnaire and interview. The obtained data were analyzed qualitatively. The results show that lecturers perceived the use of the first language as positive and part of learning process. They used the first language mainly as a pedagogical device for clarification, for establishing rapport, saving time, and discipline. The findings might have significant implications for EFL language teachers regarding the facilitative effects of $L 1$ use in the foreign language classrooms. The EFL teachers need to consider the EFL classroom context as a multilingual social space in which teachers and students take advantage of dynamic, creative and pedagogically effective use of both the target language and the learners.
\end{abstract}

Keywords: first language use, lecturers' perspective, multilingual context

\section{INTRODUCTION}

Historically the use of students' first language (L1) has been prohibited to be used in the EFL classroom, as it is considered do not benefit the students in learning the target language. During the emergence of direct method, audio-lingual method, and the communicative approach, the use of target language is strongly recommended to be used. It is due to the belief that in order to develop students' target language proficiency, the teachers must expose the students with significant amount of target language input.

However, during the post method period nowadays, the use of only the target language in the classroom is revisited. It appears worldwide in the EFL 
contexts that teachers do not only use the target language in the classroom, but they also make use of the students' language (L1) in the teaching and learning process. The scholars believe that actually the use of the first language in the English classroom is not definitely harmful. It is strongly agreed by Macaro (2001) who found out that the avoidance of L1 results in increased usage of input modification (e.g repetition, speaking more slowly, substituting basic words for more complex ones, simplifying syntax, etc). This is in turn might bring about negative effects in any interaction making the discourse less realistic, reducing the lexical diversity, and eliminating to complex syntax. Accordingly, it does not assist students in their acquisition of complex linguistic knowledge (e.g. vocabulary, phrases, and grammar). This argument supports Ellis's (1994) theory of the interactionist learning which suggests that input alone is insufficient for achieving language acquisition. To allow input readily become knowledge, there must be interaction between target language learners and other speakers. This interaction will elicit the negotiation of the meaning of the input and the production of the output. To do this, EFL learners need the use of L1.

Numerous studies concerning the use of L1 in EFL classrooms have been emerged (Brooks \& Donato, 1994; Lier, 1995; Cook 2001, Kang 2008). The studies reveal that a) L1 basically can serve as a very useful cognitive tool, providing scaffolding for students in their effort to achieve learning tasks; b) L1 enables students to negotiate meaning and communicate successfully in the target language: c) L1 provides salient input which are more easily processed by the students; and d) L1 assists students in reducing affective barriers and increasing their confidence in their ability to successfully comprehend the target language.

The use of L1 in EFL classrooms is even getting higher in multilingual communities, such as in Bali, Indonesia. In this community, people use more than one language to communicate: Balinese, Indonesian, and English. People in this context will utilize different languages for communication. The language varieties allow them to determine the language choice either consciously or consciously on certain occasions, with different interlocutors and on different topics (Holmes, 2013). In this case, people may choose which 
code/language they use to communicate. For bilinguals and multilinguals, the occurrence of language choice seems natural, automatic, and unplanned. Speakers choose an appropriate register, genre, style, medium, or tone of voice in relation to the interlocutor (who), topic (what), context (where), and medium (how) in every talk.

The same case happened in the multilingual classroom setting, in which both teachers and students have their own privileged to choose their language, as far as the language chosen can facilitate them to accomplish both the communicative purposes and the learning objectives. The use of L1 is also noticeable in the Hospitality English Classrooms in one of tourism institution in Bali, Indonesia. Both lecturers and students often make use L1 during the teaching and learning process. This paper, then, intended to find out: a) in what way do the lecturers use the L1 in the Hospitality English courses? ; and b) why do they use the L1 in their Hospitality English courses? This paper is expected can provide contribution to the language scholars in relation to the use of L1 in the EFL context, particularly in multilingual community.

\section{DISCUSSION}

\section{Context}

The study was conducted in one of tourism institutions in Bali, Indonesia. A qualitative approach was used in this study by focusing on the case study design. This is to explore the perceptions of lecturers on the use of the L1 in their classrooms. The participants were two ESP lecturers who were teaching Hospitality English (one lecturer was teaching English for Front Office Course and one lecturer was teaching English for Food and Beverage) in one of tourism vocational institutions. They had had five years teaching experience in hospitality English. They shared the same first language as the students. They were explained the research objective and given the opportunity to participate or not. They then voluntarily decided to take a part in this study. The pseudonyms were applied here. 


\section{Techniques of Data Collection and Data Analysis}

The data were collected by administering questionnaire and interview. The questionnaire included list of $21 \mathrm{~L} 1$ functions in EFL instruction in Likert scale which is adopted from Mohebbi \& Alavi (2014). The participants were required to fill in the questionnaire indicating the extent they practiced the L1 functions given in their classrooms. To triangulate the data gained from questionnaire, the interview was applied. It was to cross check and to confirm the information gathered from the questionnaire. The gained data then were analyzed qualitatively using the stages: coding the data, classifying the data, interpreting the data, and drawing the conclusion.

\section{Finding}

Having analyzed the data, it was found out that the lecturers had positive attitude toward the use of L1 in their classrooms. Both of them often used L1 during their teaching. The main function of L1 applied is showed in the following chart.

Chart 1. The Main L1 Function

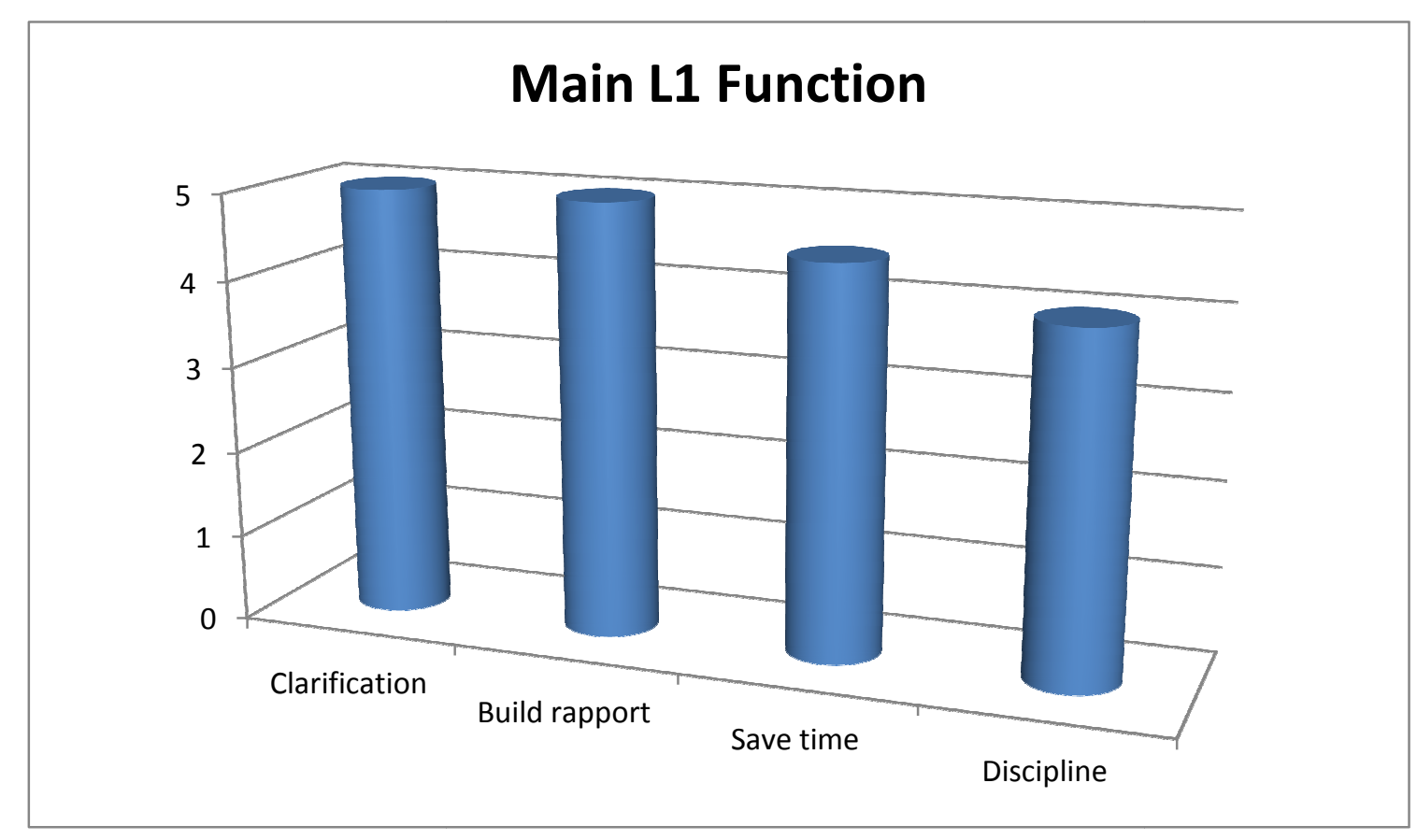


From the chart above, it is clearly seen that among the 21 list of L1 functions, clarification, building rapport, saving time, and discipline are the highest functions performed by the participants.

\section{Discussion}

The Function of L1 Used in the Classroom

Among list of 21 functions of L1, study reveals that there were four main functions which the L1 performed in the Hospitality English classrooms. They are as follows.

a) Providing clarification

Lecturers stated that they employed L1 as a teaching device for explaining aspect within the classroom such as introducing new vocabulary, explain grammar, and teaching new concepts. In Hospitality English, the learners did not only learn about the language, but also the content of the subject. For example, in English for Front Office, the course did not only cover the language used by the Front Office staff, but also the content knowledge required to be professional hoteliers. In doing so, the students commonly dealt with vocational texts consisting the contextualized vocabulary, the typical language structure, and the abstract concepts of becoming such hoteliers. Hence, in explaining and clarifying these elements, they used the L1. Firstly, they tried to explain in the target language, however, when the students seemed to require further explanations, or students asked for clarification, they used the L1. This finding basically supports the study conducted by Gregio and Gil (2007) which states that the teacher may utilize L1 as an effective strategy for the explanation of grammar and the offering feedback.

b) Building rapport

Both of the lecturers admitted that they used the L1 to build good relationship with student, as they believed that this effort would help 
them to build a joyful and less-threatening classroom which could reduce the students' anxiety toward learning English. In this case, they intentionally used the L1 in the form of joke, established humor, chitchat, etc. Additionally, they used L1 to motivate the students and to show their empathy on the struggling time experience by the students. They usually shared their past experiences when they were at the same age as their students. This is in line with Kang's (2008) case study of a Korean EFL teacher. In his study, the use of L1 improved the students' understanding on the lessons, and surprisingly increased their interest in learning English. It was because the use of L1 could lower the students' affective filter, hence they felt comfortable and confident in learning English. Gradually, their learning achievement could be reached successfully.

c) Saving time

The two lecturers stated that they used the L1 to avoid lengthy explanation in the target language and to avoid "interrupting" the pace of their lessons. It was very often that the lecturers took their initiatives to explain the lesson, especially the content knowledge in the students' language on purpose. They assumed that this way was more effective to implement that explaining in the target language. Of course, they must know the nature of the students and also the content itself. This was only held when the teachers thougt that the content knowledge was hard to be understood in the target knowledge. Instead of explaining the learning material twice (first in the target language, then the students' language), they only explained it once using the L1. Hence, it was more effective and efficient, they admitted.

d) Discipline

The lecturers indicated that they used the L1 when they were dealing with misbehavior students. Even they said that this was very seldom occurred in their classrooms, but once the disruptive behavior happens, they talked to the misbehaved students using the L1. It was to make sure that the students understood very clearly about what they said. In addition, the use of $\mathrm{L} 1$ allowed the students to express their feeling with 
Marsakawati, Language Choice in Multilingual Context: The Use of L1...

ease. Hence, it was expected that the student could talk with the students about the reasons why they misbehaved in the classroom.

\section{The Reasons Why the Lecturers Use the $L 1$ in the Classrooms}

The finding reveals that there were number of reasons why the lecturers employed the L1 in their classrooms. Firstly, the use of L1 was actually the easiest and fastest way to be implemented in the classroom since L1 was the students' first language. It was very common that the lecturers switched from the target language into the students' language or they employed code mixing during their interaction as they believed that when they used the L1, this would help the students to gain better understanding on the concepts taught. According to Pan (2009), the study on teachers code switching groups appropriate and effective code switching into three major categories: a) code switching for curriculum access, such as conveying meaning of words or sentences, explaining grammar, and displaying cultural issue; b) code switching for classroom management discourse, such as organizing tasks, disciplining, and praising the students; and c) code switching for interpersonal relations, such as the humanization of the affective climate of the classroom, i,e chatting with students and telling jokes. All these area of code switching were performed by the teachers in this context; Secondly, the level of students' English proficiency. The teachers stated that the use of their L1 was also caused by the low English proficiency of students. Even though, not all students had this low English competency, the lecturers still need the help of the L1 in their instruction. Even, they assumed this as differentiated instruction, meaning that basically their use of the L1 was intentionally to help mostly those low English competency students; and Thirdly, the use of L1 could be used to show identity. They admitted that they also used the L1 to show their identity. Even they used their native language-Balinese in the classroom. This was one way to keep maintaining and respecting their language. 


\section{CONCLUSION}

In conclusion, the use of L1 appears in the Hospitality English Courses. The lecturers used the L1 when they dealt with clarification, building rapport, saving time, and discipline. The reasons why they used the L1 were to make learning more effective and efficient, to suit with the students' English competency, and to show and keep maintaining their identity. This study can provide a contribution on revisiting the belief of using the Target Only in the EFL classrooms, even though further investigation on this issue is highly recommended, particularly to find out the voices from the students since the they are the subject of the EFL learning who will take benefit from the language choice used in the classroom.

\section{REFERENCES}

Brooks, F. \& Donato, R. (1994). Vygotskian approaches to understanding foreign language learners discourse during communicative tasks. Hispania, 77, 262-274.

Cook, V. (2001). Using the first language in the classroom. The canadian modern language review, 57(3), 402-423.

Ellis, R. (1994). The study of second language acquisition. England: Oxford University Press.

Gregio, S . \& Gil. G. (2007). Teacher's and learner' use of code switching in the English as foreign language classroom: a qualitative study. Linguage \& Ensino, 10(2),371-393.

Holmes, J. (2013). An introduction to sociolinguistics. fourth edition. USA: Routledge.

Kang, D.M. (2008). The classroom language use of a Korean elementary school EFL teaching: another look at tete. System, 36, 214-226.

Lier, L. V. (1995). The use of L1 in L2 classes. Babylonia, 2, 37-43. 
Marsakawati, Language Choice in Multilingual Context: The Use of L1...

Macaro, E. (2001). Analyzing student teacher's code switching in the foreign language classrooms: theories and decision making. The modern language journal, 85, 531-548.

Mohebbi, H. \& Alavi, S.M. (2014). An investigation into teachers' first language use in a second language learning classroom context: a questionnairebased study. Bellaterra journal of teaching and learning language and literature, 7(4), 57-73.

Pan, Y, C. (2009). The use of L1 in the foreign language classroom. Colombia applied linguistics journal, 12(2), pp (87-96). 


\section{Appendix 1}

Please mark the most appropriate option for each statement.

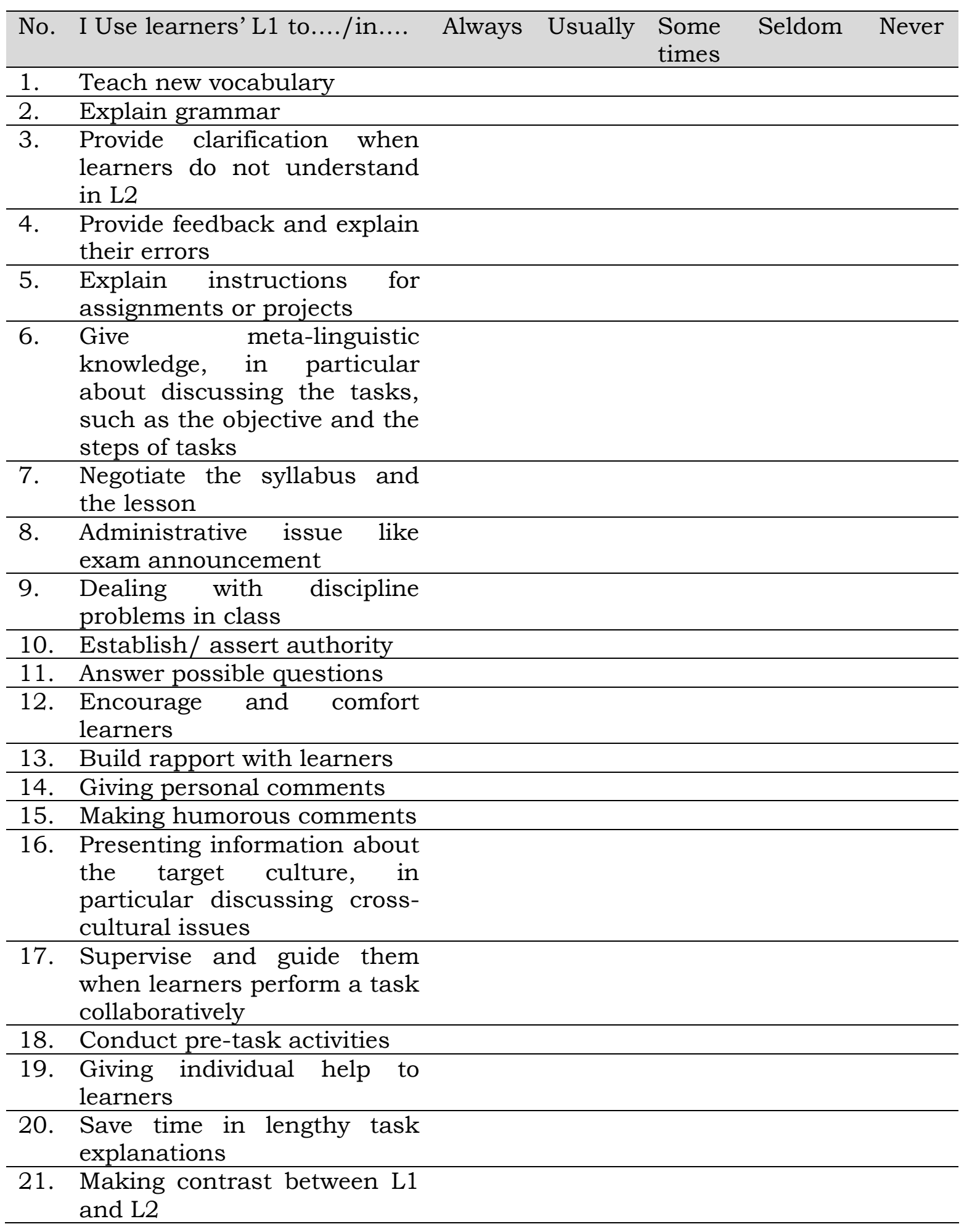

